\title{
Genetic mapping of sex-linked markers in Salix viminalis L.
}

\author{
V Semerikov ${ }^{1,3}$, U Lagercrantz ${ }^{2}$, V Tsarouhas², A Rönnberg-Wästljung ${ }^{2}$, C Alström-Rapaport ${ }^{1}$ and M \\ Lascoux $^{1}$ \\ ${ }^{1}$ Department of Conservation Biology and Genetics, Evolutionary Biology Centre, Uppsala University, Norbyvägen 18 D, 75236 \\ Uppsala, Sweden; ${ }^{2}$ Department of Plant Biology, Swedish University of Agricultural Sciences, Sweden
}

\begin{abstract}
A total of 88 selective primer combinations were screened using bulked males and females sampled from four families of Salix viminalis. A total of more than 1000 polymorphic fragments was obtained, of which only four cosegregated with sex. These four sex-linked markers were subsequently scored in individuals that were used for bulked sample preparation in additional individuals of the same families, and in individuals in other families. A pair of primers that amplified the sex-linked fragments was constructed from one of the sex-linked amplified fragment length polymorphism (AFLP) fragments. In hybridization of Southern blot filters with the sex-linked DNA fragments, the band was present in females
\end{abstract}

Keywords: Salix viminalis; sex determination; genetic map

\section{Introduction}

In most dioecious plant species, the presence of heteromorphic sex chromosomes is still disputed (Parker, 1990), and with the exception of a handful of species (eg Silene latifolia; Monéger et al, 2000) little is known about sex determination mechanisms. With the advent of the molecular age, the situation is changing rapidly but we are still far from a global picture of plant sex determination mechanisms and their evolution (Grant et al, 1994; see Ainsworth, 1999, 2000). The favored approach of most recent studies on sex determination in plants is reverse genetics: (i) identify molecular markers tightly linked to sex; (ii) screen a genomic library with the identified markers; (iii) isolate candidate gene(s) responsible for sex determination from the genomic library; and (iv) confirm gene function by complementation analysis (Terauchi and Kahl, 1999). Most of these studies have so far only reached the first stage. Sexlinked markers have recently been found in white campion (S. latifolia; Mulcahy et al, 1992), asparagus (Asparagus officinalis L.; Jiang and Sink, 1997; ReamonBüttner et al, 1998; Reamon-Büttner and Jung, 2000), kiwi plant (Actinidia chinensis; Harvey et al, 1997), pistacio (Pistacia; Hormaza et al, 1994), hemp (Cannabis sativa L.;

Correspondence: $M$ Lascoux, Department of Conservation Biology and Genetics, EBC, Uppsala University, Norbyvägen 18 D, 75236 Uppsala, Sweden.E-mail: Martin.Lascoux@ebc.uu.se

${ }^{3}$ Current address: Institute of Plant and Animal Ecology, Russian Academy of Sciences, Ekaterinburg, Russia

Received 19 April 2003 and absent in males, but the opposite pattern of band segregation (a band found in males and no band in females) was never observed in either the AFLP or RFLP experiments. Two of the sex-linked markers were placed on a linkage map. They both map at the same location in a linkage group comprising other markers not segregating with sex. Our data suggest that a single locus governs the sex determination and that nonrecombining sex chromosomes are absent in $S$. viminalis. A close association was found between skewed sex ratio and segregation distortion at this locus.

Heredity (2003) 91, 293-299. doi:10.1038/sj.hdy.6800327
Mandolino et al, 1999), hop (Humulus lupulus; Polley et al, 1997), Atriplex garrettii (Ruas et al, 1998), grapevine (Vitis; Dalbó et al, 2000) and the basket willow (Salix viminalis; Alström-Rapaport et al, 1998).

The Salicaceae (300 willow species and 30 poplar species) are noteworthy in that all but two, Populus lasiocarpa and Salix martiana, are dioecious. Only 4-10\% of all flowering plants are dioecious, and dioecy is sporadic, with occasional dioecious species in otherwise hermaphrodite genera, suggesting recurrent evolution of dioecy in plants (Parker, 1990). Another intriguing feature of many Salicaceae is their biased sex ratio. For instance, the sex ratio of the basket willow ( $S$. viminalis L., $2 n=38$ ) populations is usually strongly femalebiased, and controlled crosses suggest that sex biases are not only the result of environmental effects (AlströmRapaport et al, 1997). Interestingly, the same features, predominance of dioecy and biased sex ratios, are also found in the dioecious genus Dioscorea (Terauchi and Kahl, 1999). Another feature of both Salix and Dioscorea is the large number and small sizes of their chromosomes, making it difficult to test for the presence of heteromorphic chromosomes.

Unfortunately, little is known about the sex determination system of Salicaceae. Two previous studies (Alström-Rapaport et al, 1997, 1998) indicated that the presence of sex chromosomes is unlikely, and suggested a multilocus autosomal sex-determination system. The absence of heteromorphic sex chromosomes or chromosome-mediated sex determination in a plant species might not in itself be very surprising, as these are apparently very rare in flowering plants (Parker (1990), 
but see Guttman and Charlesworth, 1998), although one might have expected them to evolve in a genus where dioecy appeared relatively early.

The main goal of the present study was to identify and map sex-linked markers and, more specifically, to test the hypothesis that sex-determining loci were on different chromosomes as suggested by our previous studies. Bulked segregant analysis with amplified fragment length polymorphism (AFLP) was used since the AFLP technique has been successfully used to identify sexlinked markers in A. officinalis (Reamon-Büttner et al, 1998; Marziani et al, 1999; Reamon-Büttner and Jung, 2000), Dioscorea tokoro (Terauchi and Kahl, 1999) and Rumex acetosa (Ainsworth et al, 1999). The fragments segregating with sex were then converted to RFLP markers and placed on an independently generated AFLP-based map.

\section{Materials and methods}

\section{Plant material}

The $\mathrm{F}_{2}$ progeny of a factorial mating design between four male clones (X5-X8) and four female clones (X1-X4) were analyzed in the present study (Table 1). These eight clones were initially retained for studies on sex determination and sex ratio because crosses among them led to different sex ratios (Alström-Rapaport et al, 1997). The material used here is further described in AlströmRapaport et al (1997, 1998). The general strategy of the analysis is given in Figure 1.

\section{AFLPs}

DNA was extracted from leaves using the FastDNA kit (BIO 101, Inc.) according to the manufacturer's protocol with small modifications: $1 \%$ PVP-40, $0.1 \%$ of ascorbic acid and $0.1 \%$ of 2 -mercaptoethanol were added to the extraction buffer before use. The AFLP procedure (VOS et al, 1995) includes five steps: (1) restriction of DNA by two enzymes, EcoRI and MseI, and simultaneous ligation of adapters; (2) amplification of the resulting fragments

Table 1 S. viminalis analyzed for sex-linked markers

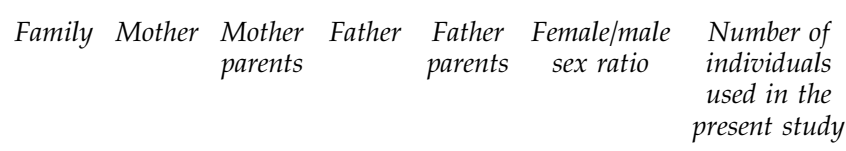

\begin{tabular}{lllllll}
\hline 115 & $970-48$ & X1, X8 & $970-89$ & X1, X8 & 1.47 & 18 \\
103 & $971-82$ & X1, X7 & $960-83$ & X3, X5 & $2.75^{*}$ & 36 \\
126 & $971-82$ & X1, X7 & $972-13$ & X4, X5 & $4.93^{*}$ & 32 \\
116 & $971-64$ & X1, X7 & $970-89$ & X1, X8 & 1.65 & 33 \\
132 & $971-64$ & X1, X7 & $968-14$ & X1, X5 & $2.36^{*}$ & 10 \\
118 & $969-72$ & X1, X6 & $970-89$ & X1, X8 & $1.58^{*}$ & 10 \\
133 & $969-72$ & X1, X6 & $968-14$ & X1, X5 & $2.17^{*}$ & 10 \\
106 & $962-41$ & X3, X8 & $960-83$ & X3, X5 & $3.35^{*}$ & 10 \\
113 & $962-87$ & X3, X8 & $975-26$ & X4, X7 & 1.40 & 10 \\
112 & $960-99$ & X3, X5 & $975-26$ & X4, X7 & 1.23 & 10 \\
110 & $973-99$ & X4, X6 & $975-26$ & X4, X7 & 1.24 & 33 \\
111 & $975-80$ & X4, X7 & $975-26$ & X4, X7 & $2.87^{*}$ & 17 \\
107 & $958-74$ & X2, X8 & $975-26$ & X4, X7 & $2.67^{*}$ & 10 \\
129 & $957-34$ & X2, X6 & $968-14$ & X1, X5 & 0.71 & 10 \\
& & & & & & \\
\hline
\end{tabular}

Families 103, 110, 126 and 116 were used in the bulked segregant analysis. *Departs significantly from 1:1 ( $\chi^{2}$ test); 55-93 individuals per family were used when estimating the sex ratio.

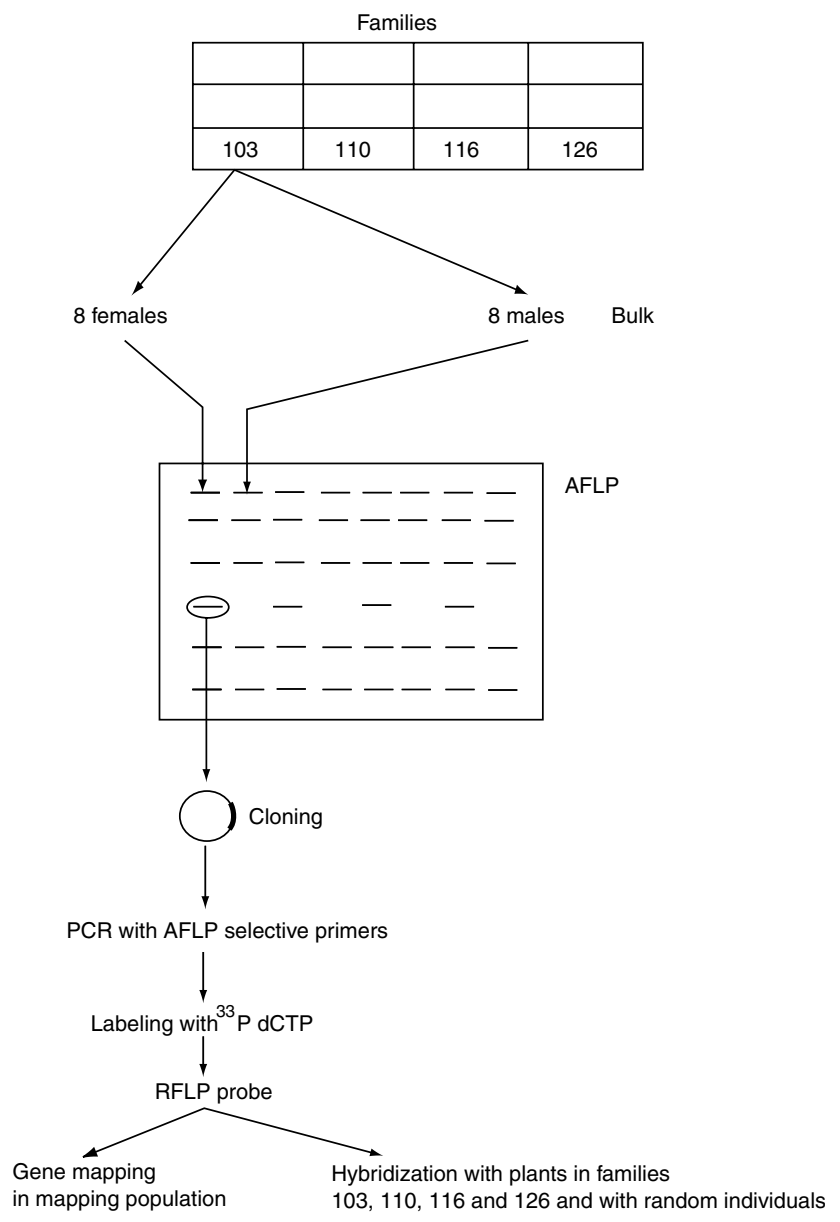

Figure 1 General experimental strategy.

with preselective primers; (3) amplification of the diluted products with selective primers (two selective nucleotides were used with the Eco primer, and three with the Mse primer, and the Eco primer was labeled with $\gamma^{33} \mathrm{P}$ ATP); (4) electrophoretic separation of the fragments in denaturing 4.5\% PAAG; (5) radioautography of the gel.

Bulked samples of eight males and eight females were prepared from preamplification products in each of families 103, 110, 126 and 116. These four pairs of bulked samples were investigated by screening 88 selective primer combinations. A band was suspected to be sex linked if it was present in one sex and absent from the other in at least two families. To verify the sex-linked pattern of these bands, their distributions were checked in individual plants of the same families and of other families in the mating scheme.

\section{Band isolation and cloning}

Bands were cut from the dried gel, DNA extracted by the 'crush and soak' method of Sambrook et al (1989) and amplified using the same PCR conditions as in the selective amplification step. The PCR product was then cleaned (QIAQUICK PCR purification kit, QIAGEN) and cloned into p-GEM T easy plasmid (Promega Co.). Positive colonies were selected according to the electrophoretic mobility of the inserted fragment. For this purpose, PCRs with the selective primers were con- 
ducted using the colonies as template. The mobility of the PCR product was compared with the corresponding AFLP fragment on the sequencing gel. At least two clones were selected and sequenced for each sex-linked AFLP marker. For one of these fragments, it was possible to design a pair of primers, allowing its amplification. The PCR conditions were 1X DynaZyme buffer (Finnzymes F-500), $0.2 \mathrm{mM}$ dNTPs, $0.2 \mu \mathrm{M}$ primer sTA-CCG1 (CAC TTC TTG GAT TTC TTC CCA CC), $0.2 \mu \mathrm{M}$ primer sTA-CCG2 (CAC CGA GGC ATT GGA GAT AAA C), $0.04 \mathrm{U} / \mu \mathrm{l}$ Taq polymerase and $\sim 1 \mathrm{ng} / \mu \mathrm{l}$ DNA.

\section{RFLPs}

In order to look at the differences between sexes in the pattern of the hybridization of sex-linked probes, a first set of RFLP experiments was conducted using 16 randomly chosen $S$. viminalis clones and some of the clones in the AFLP experiment. Plants were analyzed by Southern blot of RFLPs and hybridization with radioactively labeled cloned sex-linked AFLP fragments. Total DNA was extracted from fresh leaves according to Doyle and Doyle (1990) or from autumn buds using the protocol of Devey et al (1996); the latter gave better results than the former. A measure of $10 \mu \mathrm{g}$ of DNA was digested with EcoRV and the resulting fragments were separated at $1.5 \mathrm{~V} / \mathrm{cm}$ on $0.8 \%$ agarose gel in $1 \times \mathrm{TAE}$ buffer. After electrophoresis, DNA was transferred to a nylon HybondN+ (Pharmacia) membrane using the alkali-transfer method. The sex-linked DNA fragments used for the hybridization experiments were amplified from the corresponding plasmids using pairs of selective AFLP primers under the same PCR conditions as for the selective amplification. The resulting PCR product was then purified using the QIAquick PCR purification kit (QIAGEN). The radioactive probe was prepared from 100-200 ng of cleaned PCR product using Oligolabeling Kit (Pharmacia). The labeled mixture was then passed through Sepharose CL-6B spin column to clean the labeled probe. Prehybridization was conducted for $4 \mathrm{~h}$ at $65^{\circ} \mathrm{C}$ in Hybaid oven in a solution containing $1 \%$ dextran sulfate, $4 \times$ SETS, $10 \times$ Denhardts and $0.1 \%$ SDS. A volume of $100 \mu \mathrm{l}$ of freshly boiled herring testes DNA $(10 \mathrm{mg} / \mu \mathrm{l})$ was added to $30 \mathrm{ml}$ prehybridization solution before prehybridization. Hybridization was conducted overnight at $65^{\circ} \mathrm{C}$. The hybridization solution is the same as the prehybridization solution, but $10 \%$ dextran sulfate was used instead of $1 \%$. Hybridized filters were then washed in $2 \times \mathrm{SSC}, 0.1 \%$ SDS for $5 \mathrm{~min}$ at $65^{\circ} \mathrm{C}$, then for $15 \mathrm{~min}$ at room temperature and $1-2$ times for $15 \mathrm{~min}$ at $65^{\circ} \mathrm{C}$. After that, filters were exposed to BIOMAX Kodak film with intensifying screen $1-7$ days at $-70^{\circ} \mathrm{C}$.

\section{Genetic linkage map}

$S$. viminalis clone Jorunn and the $S$. dasyclados clone 901290 were crossed to produce $F_{1}$ seeds. Two $F_{1}$ plants were then crossed to produce the $\mathrm{F}_{2}$ mapping population. The $92 \mathrm{~F}_{2}$ individuals were scored for 756 AFLP markers. In addition, two cloned sex-linked AFLP fragments (TA-CCG and AA-CCG) were used as RFLP probes and hybridized to Southern blot filters with EcoRV- and BamHI-digested DNA from 66 individuals in the mapping population. The sex of these 66 individuals was also recorded.
A linkage map based on markers segregating in one or the other $F_{1}$ parent (1:1 segregation ratios) was constructed using MAPMAKER (version 3.0; Lincoln et al, 1992). Each resulting linkage group was thus derived from segregation in either the male or the female $F_{1}$ parent. AFLP markers segregating in both parents (3:1 segregation ratios) were then used with the program package JoinMap (Stam, 1993; Stam and Van Ooijen, 1995) to merge homologous linkage groups from the two parents. In total, 16 linkage groups are the result of segregation in either the male or the female parent. At a LOD score of 3.0, 371 markers were assigned to 49 major linkage groups (larger than $15 \mathrm{cM}$ ).

\section{Results}

\section{Bulked segregant analysis}

A total of 88 selective primer combinations were screened using bulked males and females sampled from four families. On average, 53 AFLP bands per primer combination were found to be monomorphic, 19 bands were polymorphic between families and two bands were polymorphic within some families and monomorphic in the rest of the families. Four clear and strong bands that were polymorphic in at least two families were found using four different primer combinations: (i) Eco primer bearing selective nucleotides 'AA' and Mse primer having 'CAT' selective nucleotides; (ii) Eco primer with 'AA' selective nucleotides and Mse primer with 'CAG' nucleotides; (iii) Eco primer with 'TA' and Mse primer with 'CCG'; and (iv) Eco with 'TG' and Mse with 'CAA'. The fragment sizes are 485, 192, 528 and $302 \mathrm{bp}$, and are called aAA-CAT, aAA-CAG, aTA-CCG and aTG-CAA, respectively.

The analysis of individual samples confirmed that they were cosegregating with sex. Another 11 weaker bands that were also polymorphic within some families, but monomorphic among the rest of them, were also tested in individual samples, but none was found to cosegregate with sex. The four sex-linked markers were scored in individuals that were used for bulked sample preparation, in additional individuals from the same families and in individuals from other families (Table 2). None of the AFLP fragments was completely associated with sex in the families investigated. However, for those associated with sex, the association between markers and sex was strong in most families. A pair of primers that amplified the sex-linked fragments was constructed from the sex-linked AFLP fragment aTA-CCG. The presence or absence of the PCR products obtained with these primers corresponds to the presence or absence of the AFLP fragment in most cases. This marker was designated 'sTA-CCG'. Most of the individuals were scored with this pair of primers (Table 2). Since some of the families (eg families 133 and 113, and 133 and 107) are not related to each other in the parent and grandparent generations, it is reasonable to conclude that these sexlinked markers are not specific for this experimental group, but are common to natural populations of $S$. viminalis. In general, the four AFLP fragments and the PCR marker sTA-CCG were present in females and absent in males. The discrepancies reported in Table 2 could be attributed to various causes. First, they could result from misclassifications in sex or family. However, 
Table 2 Number of individuals in each family with (first number) and without (second number) the AFLP fragments associated with sex

\begin{tabular}{|c|c|c|c|c|c|c|c|}
\hline \multirow[t]{2}{*}{ Family } & \multirow[t]{2}{*}{ Individual } & \multirow[t]{2}{*}{ Sex } & \multicolumn{4}{|c|}{ AFLP fragments } & \multirow{2}{*}{$\begin{array}{c}\text { sTA-CCG } \\
\text { PCR } \\
\text { marker }\end{array}$} \\
\hline & & & $\begin{array}{l}a A A- \\
C A T \\
485 b p\end{array}$ & $\begin{array}{l}a A A- \\
C A G \\
192 b p\end{array}$ & $\begin{array}{l}a T A- \\
C C G \\
528 b p\end{array}$ & $\begin{array}{l}a T G^{-} \\
C A A \\
302 b p\end{array}$ & \\
\hline \multirow[t]{2}{*}{103} & Males & & $4 / 11$ & $0 / 15$ & $3 / 12$ & $0 / 15$ & $1 / 14$ \\
\hline & Females & & $14 / 3$ & $17 / 0$ & $14 / 4$ & $17 / 0$ & $16 / 3$ \\
\hline \multirow[t]{2}{*}{110} & Males & & $1 / 7$ & $0 / 1$ & $1 / 7$ & $2 / 11$ & $0 / 16$ \\
\hline & Females & & $8 / 1$ & & $7 / 2$ & $11 / 2$ & $14 / 3$ \\
\hline \multirow[t]{2}{*}{111} & Males & & & & & & $0 / 6$ \\
\hline & Females & & & & & & $11 / 0$ \\
\hline \multirow[t]{2}{*}{115} & Males & & & & & & $(0 / 10)$ \\
\hline & Females & & & & & & $(0 / 8)$ \\
\hline \multirow[t]{2}{*}{126} & Males & & $0 / 8$ & $0 / 8$ & $0 / 8$ & $0 / 3$ & $0 / 14$ \\
\hline & Females & & $8 / 0$ & $16 / 1$ & $8 / 0$ & $6 / 0$ & $16 / 2$ \\
\hline \multirow{2}{*}{116} & Males & & $1 / 7$ & & & & $1 / 15$ \\
\hline & Females & & $6 / 0$ & & & & $15 / 2$ \\
\hline \multirow[t]{2}{*}{106} & Males & & $0 / 5$ & $0 / 5$ & $0 / 5$ & $0 / 5$ & $(0 / 5)$ \\
\hline & Females & & $4 / 0$ & $5 / 0$ & $5 / 0$ & $5 / 0$ & $(1 / 4)$ \\
\hline \multirow[t]{2}{*}{107} & Males & & $3 / 2$ & $2 / 3$ & $2 / 1$ & $\frac{1}{4}$ & $0 / 5$ \\
\hline & Females & & $3 / 0$ & $0 / 3$ & $2 / 0$ & $5 / 0$ & $5 / 0$ \\
\hline \multirow[t]{2}{*}{112} & Males & & $0 / 3$ & $0 / 4$ & $0 / 4$ & $0 / 4$ & $0 / 4$ \\
\hline & Females & & $6 / 0$ & $0 / 6$ & $6 / 0$ & $6 / 0$ & $6 / 0$ \\
\hline \multirow[t]{2}{*}{113} & Males & & $2 / 3$ & $1 / 4$ & $0 / 5$ & $0 / 5$ & $0 / 5$ \\
\hline & Females & & $5 / 0$ & $2 / 3$ & $5 / 0$ & $5 / 0$ & $5 / 0$ \\
\hline \multirow[t]{2}{*}{118} & Males & & $2 / 2$ & $1 / 3$ & $0 / 4$ & $0 / 4$ & $0 / 4$ \\
\hline & Females & & $5 / 1$ & $4 / 2$ & $4 / 1$ & $5 / 1$ & $5 / 1$ \\
\hline \multirow[t]{2}{*}{132} & Males & & $0 / 5$ & $0 / 4$ & $0 / 3$ & $0 / 3$ & $0 / 5$ \\
\hline & Females & & $4 / 1$ & $3 / 1$ & $4 / 0$ & $5 / 0$ & $5 / 0$ \\
\hline \multirow[t]{2}{*}{133} & Males & & $0 / 5$ & $0 / 5$ & $0 / 5$ & $0 / 4$ & $0 / 5$ \\
\hline & Females & & $5 / 0$ & $5 / 0$ & $5 / 0$ & $4 / 1$ & $5 / 0$ \\
\hline \multirow[t]{2}{*}{129} & Males & & $1 / 4$ & $1 / 4$ & $1 / 3$ & $0 / 5$ & $0 / 5$ \\
\hline & Females & & $3 / 2$ & $1 / 4$ & $5 / 0$ & $5 / 0$ & $4 / 1$ \\
\hline
\end{tabular}

The results in parentheses probably correspond to experimental artifacts.

if this were the case, one would expect all the markers to show the same pattern. Second, poor quality of DNA preparation could lead to artifacts or to inconsistent amplification. Third, experimental errors, such as contamination of the PCR mix with PCR product or plasmid DNA or sample leakage between neighboring wells in sequencing gel, cannot be completely ruled out, although all necessary precautions were taken to minimize their occurrence. Discrepancies could also be due to comigrating AFLP fragments or to restriction site mutation. The latter is most likely responsible for the absence of the aAA-CAG AFLP fragment in both males and females in the family 110 . Finally, recombination among marker loci and the locus responsible for sex cannot be ruled out.

\section{RFLP experiments}

Results of hybridization of the Southern blot filters with the cloned sex-linked AFLP fragments are shown in Table 3. Only two of the tested probes, pTA-CCG and pAA-CAG, produced RFLP bands associated with sex. The pTG-CAA probe showed no polymorphism, while the PAA-CAT probe was polymorphic but this polymorphism was not associated with sex; the failure of the last two probes is probably the result of cloning the
Table 3 Presence or absence of sex-specific RFLPs in males (m) and females (f) of families 103, 126, 110 and 116 and in the randomly chosen individuals; Probe used, size of fragment $(\mathrm{kb})$ and its presence (1) or absence (0) in the individual plant

\begin{tabular}{|c|c|c|c|c|c|c|c|c|c|}
\hline \multirow[t]{2}{*}{ Individual } & \multicolumn{8}{|c|}{$p A A-C A G$} & \multirow{2}{*}{$\begin{array}{c}p T A-C C G \\
19\end{array}$} \\
\hline & 19 & 16 & 15.5 & 14.8 & 11.6 & 9.8 & 5.0 & 3.7 & \\
\hline m 103-49 & 0 & 0 & 0 & 0 & 0 & 0 & 1 & 0 & 0 \\
\hline m 103-19 & 0 & 0 & 0 & 0 & 0 & 0 & 1 & 0 & 0 \\
\hline m 103-89 & 0 & 0 & 0 & 0 & 0 & 0 & 1 & 0 & 0 \\
\hline f $103-78$ & & & & & & & & & 1 \\
\hline f $103-88$ & 0 & 1 & 1 & 0 & 1 & 1 & 1 & 1 & 1 \\
\hline f $103-77$ & 0 & 1 & 1 & 0 & 1 & 1 & 0 & 1 & 1 \\
\hline f $103-87$ & 0 & 1 & 1 & 0 & 1 & 1 & 0 & 1 & 1 \\
\hline m 126-24 & 0 & 0 & 0 & 0 & 0 & 0 & 0 & 0 & 0 \\
\hline f $126-14$ & 0 & 1 & 1 & 0 & 1 & 1 & 0 & 1 & 1 \\
\hline f $126-23$ & 0 & 1 & 1 & 0 & 1 & 1 & 0 & 1 & 1 \\
\hline m 110-43 & 0 & 0 & 0 & 0 & 0 & 0 & 0 & 0 & 0 \\
\hline m 110-38 & 0 & 0 & 0 & 0 & 0 & 0 & 0 & 0 & 0 \\
\hline f $110-07$ & 0 & 0 & 0 & 1 & 0 & 0 & 0 & 0 & 1 \\
\hline m 116-31 & 0 & 1 & 0 & 0 & 0 & 0 & 0 & 0 & 0 \\
\hline m 116-10 & 0 & 1 & 0 & 0 & 0 & 0 & 0 & 0 & 0 \\
\hline f $116-35$ & 0 & 1 & 1 & 0 & 1 & 1 & 0 & 1 & 1 \\
\hline Prob. & & 0.02 & 0.00 & & 0.00 & 0.00 & & 0.00 & 0.00 \\
\hline M & 0 & 0 & 0 & 0 & 0 & 0 & 0 & 0 & 0 \\
\hline M & 0 & 0 & 0 & 0 & 0 & 0 & 0 & 0 & 0 \\
\hline M & 0 & 0 & 0 & 0 & 0 & 0 & 1 & 0 & 0 \\
\hline M & 0 & 0 & 0 & 0 & 0 & 0 & 0 & 0 & 0 \\
\hline M & 0 & 1 & 0 & 0 & 0 & 0 & 0 & 0 & 0 \\
\hline M & 0 & 1 & 0 & 0 & 0 & 0 & 0 & 0 & 0 \\
\hline M & 0 & 0 & 0 & 0 & 0 & 0 & 1 & 0 & 0 \\
\hline M & 0 & 0 & 0 & 0 & 0 & 0 & 1 & 0 & 0 \\
\hline F & 1 & 0 & 0 & 0 & 1 & 1 & 0 & 0 & 1 \\
\hline F & 1 & 0 & 0 & 0 & 1 & 1 & 1 & 0 & 1 \\
\hline F & 0 & 0 & 0 & 0 & 1 & 1 & 0 & 0 & 1 \\
\hline F & 0 & 0 & 0 & 0 & 1 & 1 & 1 & 0 & 1 \\
\hline F & 0 & 1 & 0 & 0 & 0 & 0 & 0 & 0 & 0 \\
\hline F & 1 & 1 & 0 & 0 & 0 & 0 & 0 & 0 & 0 \\
\hline F & 1 & 0 & 0 & 1 & 0 & 0 & 1 & 0 & 1 \\
\hline $\mathrm{F}$ & 0 & 0 & 0 & 1 & 0 & 0 & 1 & 0 & 1 \\
\hline Prob. & 0.08 & & & & 0.08 & 0.08 & & & 0.00 \\
\hline
\end{tabular}

Probability $(P)$ of independence of the band and sex was calculated using $\chi^{2}$ distribution separately for individuals from families (103, $126,110)$ and for random individuals.

wrong comigrating AFLP fragment. Selective amplification produced many weak bands, some of which could comigrate in the acrylamide gel with the targeted fragment and be excised out of the gel and cloned together with the targeted fragment. The pTA-CCG probe produced a single band that was linked to sex, while the PAA-CAG probe produced many bands some of which were linked to sex, and others not. The $19 \mathrm{~kb}$ RFLP band seems to be allelic to bands 15.5 and $3.7 \mathrm{~kb}$ (pAA-CAG probe). Indeed, the $19 \mathrm{~kb}$ band was absent in the progenies of families 103, 126, 110 and 116, but present in the random sample. Conversely, bands 15.5 and $3.7 \mathrm{~kb}$ were absent in the random sample but were present in the progenies, and they both show exactly the same segregation pattern. Obviously, larger samples of individuals will have to be tested to confirm the allelic state of the 15.5 and $3.7 \mathrm{~kb}$ bands to the $19 \mathrm{~kb}$ band. In most cases, the band was present in females and absent in males, but it is noteworthy that the opposite pattern of band segregation (a band found in males and not in 
females) was never observed in either AFLP or RFLP experiments.

\section{Segregation of markers}

In each family, we sampled 10-36 individuals with equal proportions of males and females (Table 2). The strong female association of the markers, particularly for the sTA-CCG sex primer fragment, therefore resulted in a ratio of individuals with and without the band in the samples close to 1.0 (Table 4). However, the sex ratios in the samples used in this study and in the families from which these samples were drawn are significantly different in eight of the 14 families $(103,126,118,132$, $133,106,111$ and 107). If this is taken into account, the number of individuals carrying the marker in these five families exceeds what would be expected for a 1:1 segregation. Conversely, in family 129, there is a deficit of individuals carrying the marker. The apparent segregation distortion observed in families with an excess of individuals carrying the marker can have two explanations: (1) both the mother and the father carry the marker for these five families and we get a 3:1 segregation of the marker(s); or (2) only one of the parents carries the marker, and some other genetic phenomenon causes the distortion. If both parents carried the marker, then we would expect a 1:1 segregation of the marker in the male progeny, which was not observed for any of the crosses (Table 2). Assuming that only one parent in each family, in this case the mother, carries the marker, the skewed marker segregation ratios and sex ratios observed in some families must be explained by some other factor. For example, an excess of individual plants carrying the marker could be caused by reduced germination of seeds in which the marker is absent. However, germination tests show that the proportion of germinated seeds was high in all families (Table 4). Reduced germination therefore fails to explain the skewed segregation in family 126, 132 and 129. The segregation distortion must have occurred prior to or at the time of fertilization. Segregation of a recessive lethal allele at a linked locus, differential gametic viability or unequal gamete segregation at meiosis could all explain our data.

\section{Mapping of the sex-linked fragments}

The female-to-male ratio of the mapping population was 1.6. The probe pTA-CCG revealed a single polymorphic locus (hereafter designated as 'pTA-CCGa') that segregated perfectly with sex. The pAA-CAG probe detected two polymorphic loci, one of which segregated perfectly with sex (hereafter designated as 'pAA-CAGb'), while the second showed no linkage to sex. At a LOD score above seven, the two cosegregating sex-linked loci (and sex itself) mapped to a linkage group derived exclusively from markers segregating in the female parent (Figure 2). The length of the linkage group was $60 \mathrm{cM}$, indicating frequent recombination along the chromosome containing the sex-determining locus.

\section{Discussion}

\section{Female-associated markers}

Bulked segregant analysis revealed four AFLP fragments associated with sex in $S$. viminalis. The four fragments showed the same pattern in all families studied; they were present in almost all females and absent in nearly all males. This is also true for the sex-linked RAPD marker that was found previously (Alström-Rapaport et al, 1998) and it suggests that males differ from females by the absence of some chromosomal fragments. Support for this is provided by the fact that RFLPs derived from two of the AFLPs associated with sex, namely the single $19 \mathrm{~kb}$ pTA-CCG restriction fragment and five pAA-CAG fragments, are specific to females. RFLP markers based on two out of the four sex-linked fragments (probe pAA-CAG and pTA-CCG) mapped to the same location (Figure 2). The segregation patterns of the two AFLP fragments aAA-CAT (485 bp) and aTG-

Table 4 Marker segregation and sex ratio

\begin{tabular}{|c|c|c|c|c|c|}
\hline Family & $\begin{array}{l}\text { Presence/absence ratio } \\
\text { of the sTA-CCG } \\
\text { sex primer fragment }\end{array}$ & $\begin{array}{l}\text { Female/male ratio } \\
\text { of individuals used } \\
\text { in this study }\end{array}$ & $\begin{array}{c}\text { Female/male ratio of } \\
\text { all progeny }\end{array}$ & $\begin{array}{c}\text { Estimated presencelabsence } \\
\text { ratio of fragment for } \\
\text { all progeny }\end{array}$ & $\begin{array}{l}\text { Prop. Germinated } \\
\text { seeds }\end{array}$ \\
\hline 115 & - & 0.80 & 1.47 & - & 0.87 \\
\hline 103 & 1.00 & 1.27 & $2.75^{*}$ & 1.75 & - \\
\hline 126 & 1.00 & 1.29 & $4.93^{*}$ & 2.83 & 0.99 \\
\hline 116 & 0.94 & 1.06 & 1.65 & 1.35 & 0.94 \\
\hline 132 & 1.00 & 1.00 & $2.36^{*}$ & 2.36 & 0.93 \\
\hline 118 & 1.00 & 1.50 & $1.58^{*}$ & 1.05 & 0.89 \\
\hline 133 & 1.00 & 1.00 & $2.17^{*}$ & 2.17 & 0.97 \\
\hline 106 & - & 1.00 & $3.35^{*}$ & 0.23 & 0.84 \\
\hline 113 & 1.00 & 1.00 & 1.40 & 1.40 & 0.83 \\
\hline 112 & 1.50 & 1.5 & 1.23 & 1.23 & 0.91 \\
\hline 110 & 0.74 & 1.06 & 1.24 & 0.84 & - \\
\hline 111 & 1.83 & 1.83 & $3.87^{*}$ & 3.87 & - \\
\hline 107 & 1.00 & 1.00 & $2.67^{*}$ & 2.67 & - \\
\hline 129 & 0.67 & 1.00 & 0.71 & 0.5 & 0.86 \\
\hline
\end{tabular}

The second and third columns give the observed ratio of individuals with/without the sTA-CCG sex primer marker and sex ratio in the studied samples, respectively. The third and fourth columns give the sex ratio and the estimated ratio of individuals with/without the sTACCG sex primer marker in the whole family. The last column gives the proportion of germinated seeds for each family. ${ }^{*}$ Departs significantly from 1:1 ( $\chi^{2}$ test). - denotes nonavailable data. 


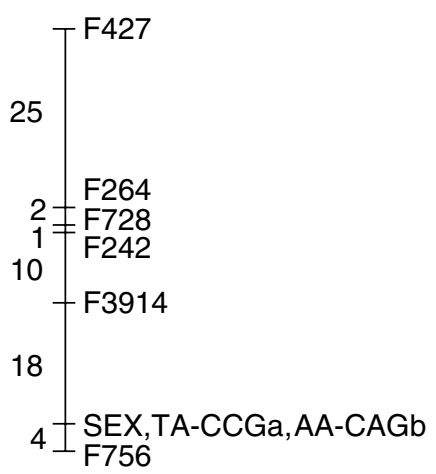

Figure 2 Linkage group carrying sex-linked markers. The linkage group is derived from AFLP markers segregating in the female parent and two sex-linked RFLP markers (pTA-CCGa, pAA-CAGb). Both RFLP markers cosegregated with sex. Recombination distances are given in Kosambi centimorgans.

CAA (302 bp), which could not be mapped because they were not successfully cloned, are almost identical to the two mapped fragments in 13 families (Table 2). We therefore conclude that the four fragments are closely located physically or are physically separated but reside in an area where recombination is limited.

The pattern in S. viminalis is exactly the opposite to that observed in D. tokoro (Terauchi and Kahl, 1999), Asparagus (Jiang and Sink, 1997; Reamon-Büttner et al, 1998), A. garrettii (Ruas et al, 1998), C. sativa (Mandolino et al, 1999) and H. lupulus (Polley et al, 1997), where the sex-linked AFLP/RAPD fragment was present in males and absent in females. In all these cases, it was already known or could be inferred that the male was the heterogametic sex and the female homogametic. This can apparently be ruled out in $S$. viminalis. The pattern observed in S. viminalis is similar to that observed in Pistacia vera (Hormaza et al, 1994).

Sex chromosomes versus single sex-determination locus The large number of primer pairs used and polymorphic fragments, more than 1000, resulted in only four sexlinked fragments that appear to be closely linked. Assuming that the 1000 fragments are evenly distributed over the genome, we expect around 27 segregating fragments per chromosome. Likewise, a large number of RAPD primers were tested in a previous study that resulted in a single sex-associated marker. In comparison, using 60 RAPDs primer pairs, four sex-linked markers were found for a single family of S. latifolia which has distinct heteromorphic sex chromosomes (Mulcahy et al, 1992). Clearly, the presence of a sex determination system similar to that of S. latifolia is not likely for $S$. viminalis. On the contrary, our results suggest that a very restricted region of the chromosome is involved in sex determination.

\section{Why have not sex chromosomes evolved?}

As concluded by Alström-Rapaport et al (1998), there are apparently no sex chromosomes in S. viminalis. Before discussing the absence of nonrecombining sex chromosomes, a few words on the genetic map are necessary. The linkage map has not yet coalesced to the 19 groups one would expect from the known chromosome number in S. viminalis and it is likely that some of the minor linkage groups will cluster with major ones when more markers are added and/or an extended pedigree population is used. However, a better map will not change our conclusions regarding the absence of sex chromosomes, although it will probably change the structure of the linkage group(s) carrying sex-determining loci. The linkage group was derived from markers segregating exclusively in the female parent. A more comprehensive map will identify the homologous linkage group derived from segregation in the male parent. A comparison of these two linkage groups could reveal structural differences between chromosomes carrying male- and female-determining genes. As stated previously, our data suggest that males differ from females by the absence of some chromosomal segments.

So, why have not sex chromosomes evolved in S. viminalis, a species belonging to a genus in which almost all species are dioecious? Preliminary results suggest that other willow species differ from $S$. viminalis. The sex-linked markers developed in S. viminalis failed to cosegregate with sex in $S$. caprea (V Semerikov, unpublished data) and SCAR markers developed from the RAPD band found by Alström-Rapaport et al (1998) in $S$. viminalis have so far given mixed results in $S$. eriocephala (LE Gunter, personal communication). If confirmed, these results would indicate that there is no ancient sex-determination system shared by all willow species, or at least that the area around it has not been conserved. In Silene, dioecy has probably evolved twice within a period estimated to be between 8 and 24 million years (Desfeux et al, 1996). Hence, sex chromosomes can evolve in a relatively short period of time. A recent molecular phylogeny of the Salicaceae (Leskinen and Alström-Rapaport, 1999) using ribosomal DNA sequences (5.8S, ITS1 and ITS2) found very low sequence divergence between species. Salix fossils have been retrieved from the Eocene, 55-65 MYA (Collinson, 1992). This suggests a very low rate of sequence evolution with substitution rates of $0.4 \times 10^{-9}$ substitutions per year, assuming a divergence of Salix species 40 MYA (Leskinen and Alström-Rapaport, 1999). Perhaps the same low rate of evolution also applies to sexdetermination systems, explaining the maintenance of a single or multilocus sex determination system in some if not all species of Salix. This however supposes that slow sequence evolution is coupled to slow structural genome evolution, a relationship that, to the best of our knowledge, is not established.

\section{Acknowledgements}

The Swedish Council for Agricultural and Forestry Research (SJFR, now FORMAS) and the Swedish Energy Agency supported this work. VLS was supported in part by the Swedish Royal Academy of Sciences. We thank Deborah Charlesworth for very useful comments that helped improve a previous version of the article.

\section{References}

Ainsworth CC (1999). Sex Determination in Plants. Bios Scientific Publishers: Oxford.

Ainsworth CC (2000). Boys and girls come out to play: the molecular biology of dioecious plants. Ann Bot 86: 211-221. 
Ainsworth CC, Lu J, Winfield M, Parker J (1999). Sex determination by $\mathrm{X}$ : autosome dosage: Rumex acetosa (sorrel). In: Ainsworth CC (ed) Sex Determination in Plants, Bios Scientific Publishers: Oxford. pp 149-162.

Alström-Rapaport C, Lascoux M, Gullberg U (1997). Sex determination and sex-ratio in Salix viminalis L. Theor Appl Genet 94: 493-497.

Alström-Rapaport C, Lascoux M, Wang YC, Roberts G, Tuskan GA (1998). Identification of a RAPD marker linked to sex determination in the basket willow, Salix viminalis L. I Hered 89: 44-49.

Collinson ME (1992). The early fossil history of Salicaceae: a brief review. Proc R Soc Lond B 98: 155-167.

Dalbó MA, Ye GN, Weeden NF, Steinkellner H, Sefc KM, Reisch BI (2000). A gene controlling sex in grapevines placed on a molecular-based genetic map. Genome 43: 333-340.

Desfeux C, Maurice S, Henry JP, Lejeune B, Gouyon PH (1996). Evolution of reproductive systems in the genus Silene. Proc $R$ Soc Lond B 263: 409-414.

Devey ME, Bell JC, Smith DN, Neale DB, Moran GF (1996). A genetic linkage map for Pinus radiata based on RFLP, RAPD, and microsatellite markers. Theor Appl Genet 92: 673-679.

Doyle JJ, Doyle JL (1990). Isolation of plant DNA from fresh tissue. Focus 12: 12-15.

Grant S, Houben A, Vyskot B, Sirikovy J, Pan WH, Macas J et al (1994). Genetics of sex determination in flowering plants. Dev Genet 15: 214-230.

Guttman DS, Charlesworth D (1998). An X-linked gene with a degenerate Y-linked homologue in a dioecious plant. Nature 393: 263-266.

Harvey CF, Gill GP, Fraser LG, McNeilage MA (1997). Sex determination in Actinidia. 1. Sex-linked markers and progeny sex ratio in diploid A. chinensis. Sex Plant Reprod 10: $149-154$

Hormaza JI, Dollo L, Polito VS (1994). Identification of a RAPD marker linked to sex determination in Pistacia vera using bulked segregant analysis. Theor Appl Genet 89: 9-13.

Jiang C, Sink KC (1997). RAPD and SCAR markers linked to the sex expression locus $M$ in asparagus. Euphytica 94: 329-333.

Leskinen E, Alström-Rapaport C (1999). Molecular phylogeny of Salicaceae and closely related Flacourtiaceae: evidence from 5.8S, ITS1 and ITS2 of the rDNA. Plant Syst Evol 215: 209-227.
Lincoln S, Daly M, Lander E (1992). Constructing Genetic Maps with MAPMAKER/EXP 3.0, 3rd edn. Whitehead Institute Technical Report.

Mandolino G, Carboni A, Forapani S, Faeti V, Ranalli P (1999). Identification of DNA markers linked to the male sex in dioecious hemp (Cannabis sativa L.). Theor Appl Genet 98: 86-92.

Marziani G, Caporali E, Spada A (1999). Search for genes involved in asparagus sex-determination. In: Ainsworth CC (ed) Sex Determination in Plants, Bios Scientific Publishers: Oxford. pp 149-162.

Monéger F, Barbacar N, Negrutiu I (2000). Dioecious Silene at the X-road: the reason Y. Sex Plant Reprod 12: 245-249.

Mulcahy DL, Weeden NF, Kesseli R, Carroll SB (1992). DNA probes for the Y-chromosome of Silene latifolia a dioecious angiosperm. Sex Plant Reprod 5: 86-88.

Parker JS (1990). Sex chromosomes and sexual differentiation in flowering plants. Chromosome Today 10: 87-98.

Polley A, Seigner E, Ganal MW (1997). Identification of sex in hop (Humulus lupulus) using molecular markers. Genome 40 : 357-361.

Reamon-Büttner SM, Jung C (2000). AFLP-derived STS markers for the identification of sex in Asparagus officinalis L. Theor Appl Genet 100: 432-438.

Reamon-Büttner SM, Schondelmaier J, Jung C (1998). AFLP markers tightly linked to the sex locus in Asparagus officinalis L. Mol Breeding 4: 91-98.

Ruas CF, Fairbanks DJ, Evans RP, Stutz HC, Andersen WR, Ruas PM (1998). Male-specific DNA in the dioecious species Atriplex garrettii (Chenopodiaceae). Am J Bot 85: 162-167.

Sambrook J, Fritsch EF, Maniatis T (1989). Molecular Cloning. A Laboratory Manual, 2nd edn. Cold Spring Harbor Laboratory Press: Cold Spring Harbor, NY.

Stam P (1993) Construction of integrated genetic linkage maps by means of a new computer package: JoinMap. Plant $J 3$ : 739-744.

Stam P, Van Ooijen JW (1995). Join Map ${ }^{\mathrm{TM}}$ Version 2.0: Software for the Calculation of Genetic Linkage Maps. CPRO-DLO, Wageningen.

Terauchi R, Kahl G (1999). Sex determination in Dioscorea tokoro, a wild yam species. In: Ainsworth CC (ed) Sex Determination in Plants, Bios Scientific Publishers: Oxford. pp 149-162.

Vos P, Hogers R, Bleaker M (1995). AFLP: a new technique for DNA fingerprinting. Nucleic Acids Res 23: 4407-4414. 